\title{
Country Focus
}

"Country Focus" includes news of a more detailed and substantive kind than the news items given in "News in Brief from Statistical Offices".

\section{Denmark}

\section{New Organization at Statistics} Denmark: "Organization 95"

With effect from 1 September 1995 major organizational changes are carried out by Statistics Denmark. Among the most significant changes are:

- that the environment and energy statistics are merged in a highly professional division responsible for the environment and energy. In this field, considerable developments are aimed at over the next few years;

- that a new division is established for statistics on the services sectors, i.e. wholesale and, retail trade, transport, tourism and services. In this growing business area, an improvement in the statistical coverage is also expected;

- that the general and sectorally oriented business statistics are now merged in one department for business statistics;

- that a new department for user services is established. are:

The objectives of "Organization 95"

- To strengthen the quality and effi- ciency of the professional work in the field of statistics. To this end, three homogeneous departments, which are engaged only in activities relating to business, economic and persons statistics, are established. Previously, these subjectareas were divided over several departments, but a new department is now established for each area.

- To strengthen the usefulness and service-orientation of Statistics Denmark's products and to ensure a cohesive and up-to-date dissemination of the statistics. The external as well as in-house services are upgraded through the establishment of a new department for user services, which merges user-oriented activities previously divided over several departments.

- To strengthen the international statistical collaboration by establishing a new Management Secretariat, with coordinated task and with an upgrading of the activities relating to systems export.

- To achieve a more comprehensible organizational structure. From a user's point of view it is important to be able quickly to get an overview of where to apply a request or a problem. From Statistics Denmark's point of view it is also important that the signals to interested parties and the public are unambiguous. Such considerations are allowed for by the new organization in respect of, e.g., the com- 
mercial sector, the research world and the public sector.

\section{Republic of Slovenia}

\section{New Slovenian Law on National Statistics}

The new Slovenian Law on National Statistics was promulgated on $4 \mathrm{Au}$ gust 1995 and entered into force on 19 August 1995. The law embraces 62 Articles, which are divided into 11 Chapters.

According to the contents of the law, the main principles of statistical function in Slovenia are based on: neutrality, objectivity and professional independence. Furthermore, the Statistical Office of the Republic of Slovenia as a professionally independent organisation performs the primary tasks of national statistics.

Reporting is mandatory for all reporting units which are defined by the law and the national statistical programme. When obligatory reporting is not defined in collecting statistical data, the basis for reporting is the consent of the reporting unit.

The professional tasks that the Statistical Office of the Republic of Slovenia performs are determined by this law in a very precise manner. Moreover, the law determines the establishment of a special advisory body dealing with strategic and development issues in national statistics, i.e., the Statistical Council of the Republic of Slovenia. The members of the Council are defined by this law and consist of 12 representatives of the legislative, executive and judicial branches, the Central Bank, employers, employees and independent statistical experts. The 13th member of the Council is the Director of the Statistical Office of the Republic of Slovenia, who is also the President of the Statistical Council. Other Statistical Advisory Committees for individual fields of national statistics will also be established. The members of these bodies will be appointed by the Director of the Statistical Office of the Republic of Slovenia.

The Law on National Statistics includes other important topics. Some of the most important are: the five-year annual national statistical programme; the methodological bases of statistical surveys; administrative and statistical registers (the Statistical Office of the Republic of Slovenia is trying to create a register-oriented statistical system, which will be very similar to the Danish statistical system); data protection and statistical confidentiality, international statistical co-operation, etc. 